\title{
2D AND 3D PLOTTER USING ARDUINO NANO
}

\author{
Jagadeesh Kumar Chougala \\ Department of EEE \\ BMS College of Engineering, Bangalore, \\ Karnataka, India \\ Jayanth H S \\ Department of EEE \\ BMS College of Engineering, Bangalore, \\ Karnataka, India
}

\author{
Kirankumar S Patil \\ Department of EEE \\ BMS College of Engineering, Bangalore, \\ Karnataka, India \\ Santhosh M P \\ Department of EEE \\ BMS College of Engineering, Bangalore, \\ Karnataka, India
}

\author{
Chaitanya. L \\ Assistant Professor \\ Department of EEE \\ BMS College of Engineering, Bangalore, \\ Karnataka, India
}

\begin{abstract}
This paper aims to develop and implement a low cost and high accuracy mini-CNC machine for $2 \mathrm{D}$ and $3 \mathrm{D}$ plotting using Arduino Nano. This system can be widely used in small-scale engraving or Image plotting applications where the accuracy and speed are the main performance parameters.
\end{abstract}

Keywords- CNC, 2D-3D Plotter, G-Code, INKSCAPE, Engraver master, universal G-code sender (UGS), Proteus.

\section{INTRODUCTION}

$\mathrm{CNC}$ is an advanced form of automatic machine used to control the motion of a machine. It works mainly on 3 steps that are receiving data, interpreting data and reacting accordingly to received data. It has many advantages like high efficiency, higher flexibility, low production cost and less working time. These qualities make it unique and more recommended. Generally, CNC machines are used to process a piece of material such as plastic, metal, wood, ceramic or composite material to take the specification by following a coded program instruction such as Geometric code (G-code) without any intervention of manual operator. There are different types of CNC machines based on requirements such as CNC Lathe Machine, CNC Milling Machine and CNC Plasma Cutting Machine [1].

The Small-scale industries generally face problems related to increased competition, insufficient capital, requirement of more wages for skilled workers. This paper proposes Arduino Nano based CNC Machine which is cost effective with precision thereby reducing the initial cost to a certain extent and the proposed machine can be used for $2 \mathrm{D}$ and $3 \mathrm{D}$ plotting for small scale industries.

\section{MODELLING}

The proposed system enables to plot 2D or 3D sketch on various materials [2] [3]. The overall block diagram for the proposed system shown in Fig 1. A 2D plotter requires two stepper motors whereas a 3D plotter requires three stepper motors and this proposed combined $2 \mathrm{D}$ and $3 \mathrm{D}$ plotter is controlled using an Arduino Nano.

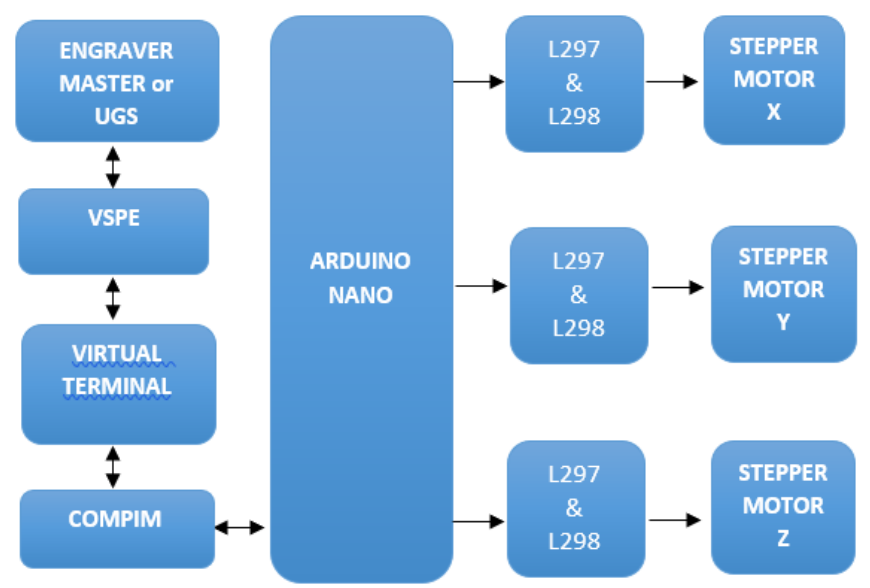

Fig. 1. Block Diagram of proposed system

The stepper motors are used for tracing and plotting purpose in various directions. These stepper motors are driven using three sets of L298 and L297 motor drivers. These drivers are 
controlled by a Arduino nano microcontroller which provides the necessary control signals so as to trace the given image or plot as per the required applications [4]. For 2D and 3D plotting the required image or sketch is converted into the necessary G-code by using the Inkscape software for $2 \mathrm{D}$ and Autodesk fusion 360 for 3D [6].

Initially connection is built between Arduino board and Engraver master for 2D images, UGS for 3D with the help of VSPE which acts as a virtual connecter. In simulation Virtual terminal is used for sending and receiving of data, COMPIM acts as serial port terminal of computer. Once the connection is established between the VSPE, PROTEUS and Engraver Master. The generated G-code of 2D image is loaded to the Engraver master software or generated G-code of 3D image is loaded to UGS, which sends G-code to Arduino Nano where the code is decoded to generate the required pulses which is used to control the stepper motors movement using drivers L297 and L298. The movement of stepper motors will aid the spindle of the plotter to trace the required image on the necessary material which can also be visualised using the Engraver master or UGS.

\section{METHODOLOGY}

The simulation of the proposed system is carried out using Proteus professional 8.6[8]. The simulation model is shown in Fig 2, where TX and RX pins which are known as Transmitting and Receiving pins of Arduino Nano are used as Serial communication between computer and Arduino Nano board, to ensure that any data sent to Arduino Nano is also sent to PC. Here the operating voltage of Arduino Nano is $5 \mathrm{~V}$. These two pins are connected to COMPIM.

COMPIM is used to model COM interfaces in Proteus. COMPIM acts as serial port of computer so that it can receive data from another software or from external hardware. In this proposed system it is used to receive data from external software Engraver master or UGS. COMPIM's TX and RX pins are connected to Virtual terminal for sending and receiving data.

Output pins of Arduino Nano is connected to three sets of L297 which is used to control the direction of motor in steps and magnitude of load current. It is activated by giving 5VDC to ENABLE pin. Output of L297 is given to L298 which is used to control the drive power of stepper motor and also provide over temperature protection to stepper motor. L298 output leads are connected to the three stepper motors. COM1 port is selected in COMPIM with baud rate of 9600.Connection between VSPE and Proteus is built through COMPIM.

VSPE acts as a connecting bridge between the Engraver master or UGS and PROTEUS software. So, to build connection in Engraver master or UGS same serial port and baud rate is selected as that of COMPIM. The 2D image which is converted into G-code using INKSCAPE follows a sequence of steps for conversion as shown in Fig 2. INKSCAPE is an open-source vector graphics editor used to create vector images, primarily in scalable vector graphics format [5].

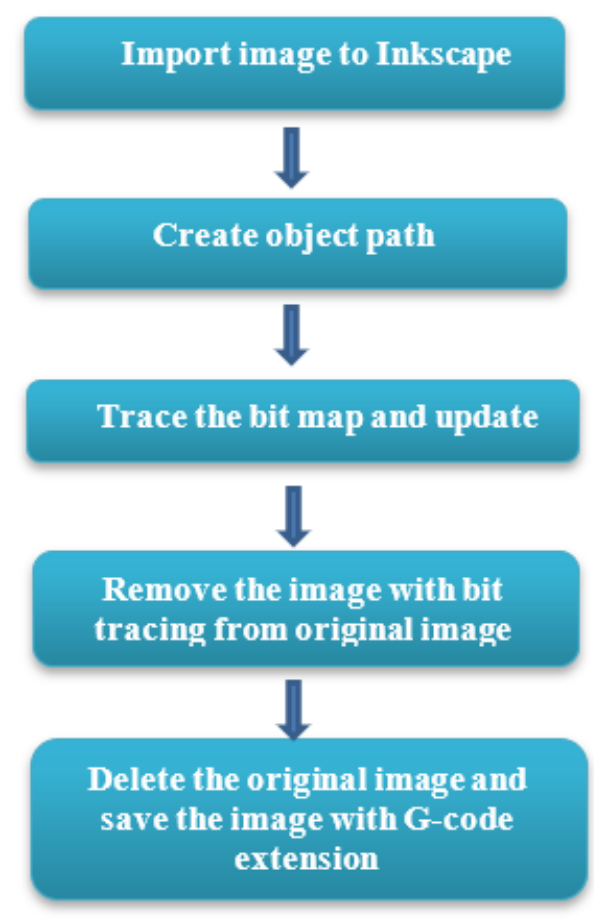

Fig 2. Steps for G-code generation

The generated G-code is loaded into Engraver master. Engraver master is an open source, most commonly used graphic design and layout software tool. The G-code received from Engraver master is decoded in Arduino Nano and converted into digital signals. These signals are provided as input to L297 which has an operating voltage of 10V. L297 has two PWM chopper circuits These PWM chopper circuits generate driving signals. These generated signals are given to L298. L298 has input voltage range of $5-35 \mathrm{~V}$ and generates voltage of $46 \mathrm{Vand}$ has an output current of 2A. L298 has H-Bridge configuration which generates 46VDC. The output voltage of L298 is given as input to the stepper motor which has motor winding current of $2 \mathrm{~A}$ and $46 \mathrm{~V}$ as input voltage and it is a bipolar stepper motor [7]. Stepper motors move according to the G-code. So, there are three stepper motors for $\mathrm{X}, \mathrm{Y}$ and $\mathrm{Z}$ axis respectively. $\mathrm{X}$ axis stepper motor is used for movement corresponding to horizontal direction, $\mathrm{Y}$ axis stepper motor is used for movement corresponding to vertical direction and $\mathrm{Z}$ axis stepper motor is used depth specification. Movement of these stepper motor is sent back to Engraver master as the feedback and it also displays the virtual engraving of the require pattern of the loaded G-code. 


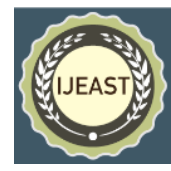

And the same process is repeated for $3 \mathrm{D}$ image but the difference lies in the software tool used. Here instead of Engraver master, UGS (Universal G-code Sender) is used. UGS is full featured G-code platform used for interfacing with advanced CNC controllers like GRBL, TinyG, g2core and Smoothieware.

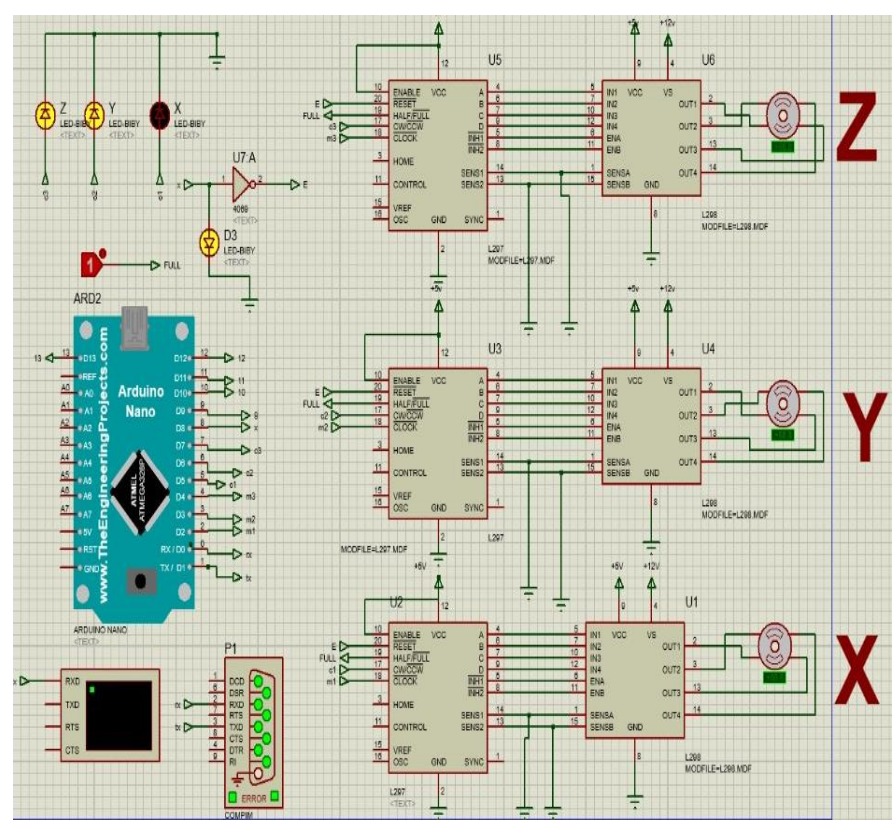

Fig. 3. Proteus model of the Proposed system

\section{RESULTS AND DISCUSSION}

Fig 3 shows the Engraving of a 2D image which is done using Engraver master. The G-code is uploaded before the start of the process as shown in Fig 4. Once the process commences the engraving of the $2 \mathrm{D}$ image starts which is indicated by green engraving as shown in Fig 5. In the similar way the entire image will be traced with the green engraving as shown in Fig.6.

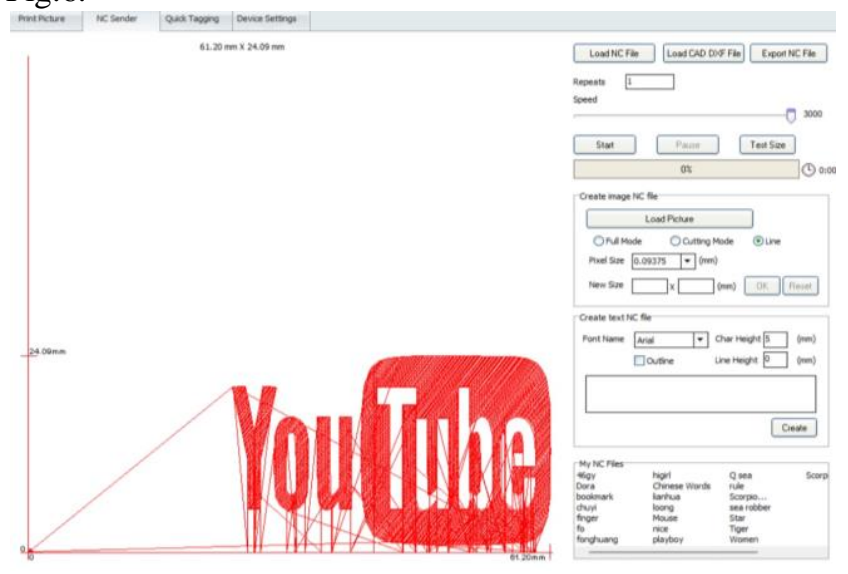

Fig 4. 2D image in Engraver Master

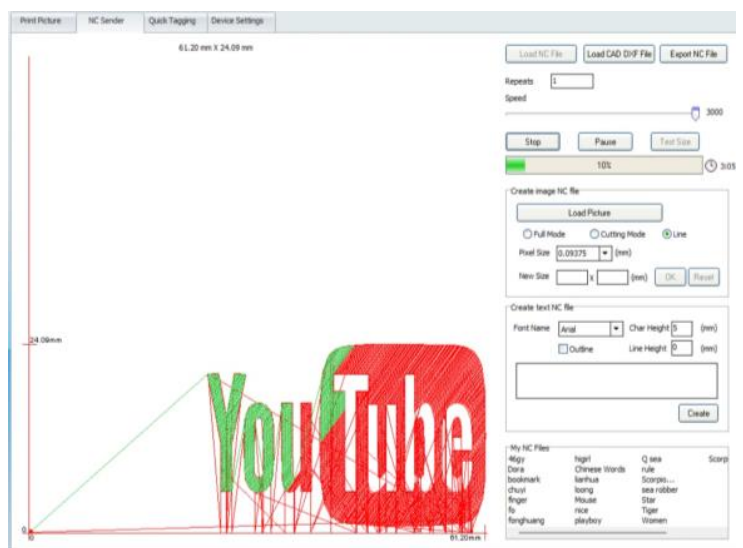

Fig 5. Result of 2D image in Engraver Master.

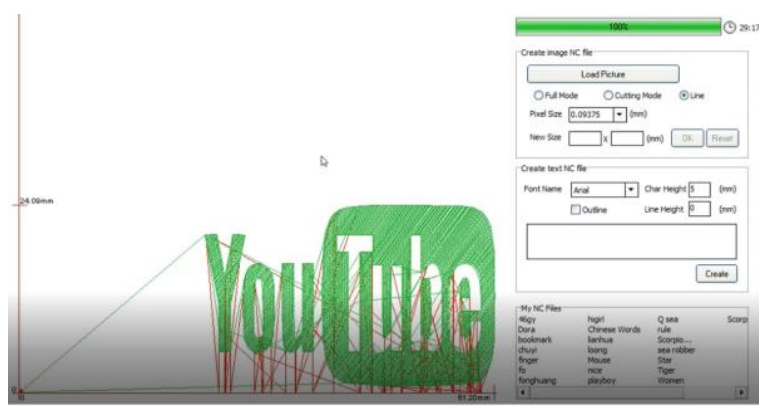

Fig 6. Result of 2D image in Engraver Master after completion of tracing.

The Engraving is carried for a 3D image which is done using UGS. Here the G-code of the 3D image is uploaded before the start of the process shown in Fig7. Once the process commences it is observed that the engraving of the 3D image has started and is indicated by yellow line shown in Fig 8. The yellow line continues to trace the image until completion.

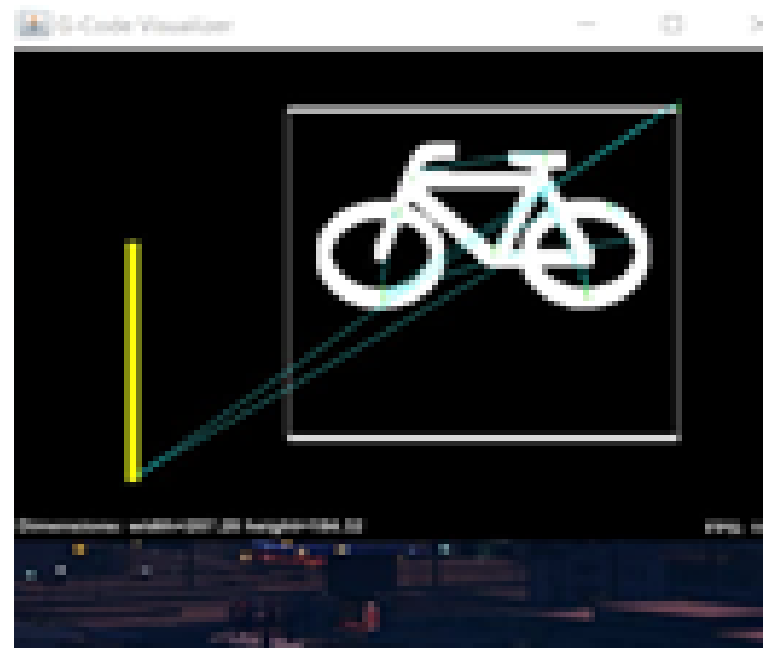

Fig 7. 3D image in UGS. 
International Journal of Engineering Applied Sciences and Technology, 2021

Vol. 6, Issue 1, ISSN No. 2455-2143, Pages 331-334

Published Online May 2021 in IJEAST (http://www.ijeast.com)

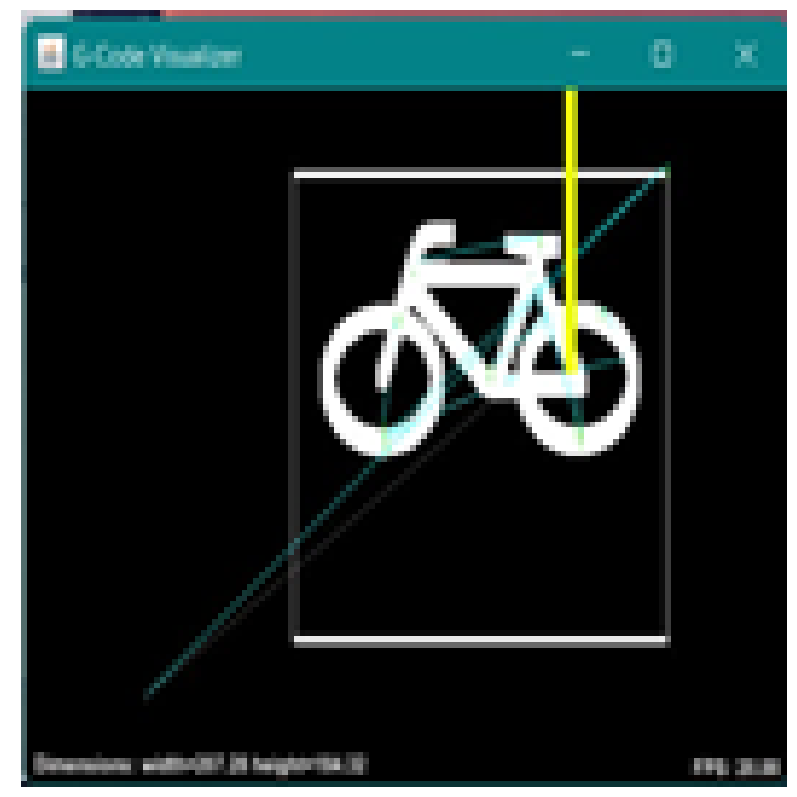

Fig 8. Results of 3D image in UGS while tracing is in process.

\section{CONCLUSION}

Thus, the simulation of the combined 2D and 3D plotter with Arduino nano is been carried out using the Proteus platform and the same can be implemented to provide high accurate and low-cost solution for small scale industry application. The hardware implementation of the proposed system will reduce the cost by around 50 percent when compared to the existing system being used in small scale industries.

\section{REFERENCES}

[1] Study on computer numerical control (CNC) machines Venkata Ramesh Mamilla,Srinivasulu M, Mani Prasad N,International Journal of Advanced Scientific Research ISSN: 2456-0421.

[2] K.S.Prajhwal1, K.S.Sabarish2, S.Karan3, A.Subhashnan4, K.Ragunath5 " 2D Plotter Machine” 2020 | IJIRT | Volume 6 Issue 11 | ISSN: 2349-6002

[3] Ghulam Dastgeer, Prof. Muhammad Asad, Saad. S.S. Ali "Wireless Base CNC Mini Plotter Three Axis Control Machine"2018 International Research Journal of Engineering and Technology (IRJET)

[4] Yusuf Abdullahi Badamasi Nigerian Turkish Nile University "The Working Principle of An Arduino". 2014 IEEE
[5] Alex Bigelow, Steven Drucker, Danyel Fisher, and Miriah Meyer "Iterating Between Tools to Create and Edit Visualizations"2016 IEEE

[6] Y M Qi2and D C Cai3Tianjin University of Technology and Education, Tianjin "Research and Application of Autodesk Fusion360 in Industrial Design" 2018 International Conference on Computer Information and Automation Engineering.

[7] Tanu Shree Roy, Humayun Kabir, Md A. Mannan Chowdhury "Simple Discussion on Stepper Motors for the Development of Electronic Device" January-2014International Journal of Scientific \& Engineering Research, Volume 5,Issue1.

[8] Katya Asparuhova,Daniela Shehova and Slavi Lyubomirov "Using Proteus to Support Engineering Student Learning: Microcontroller-Driven Sensors Case"2018 IEEE. 